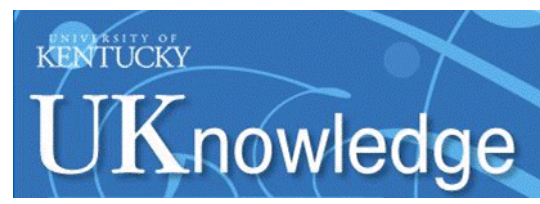

University of Kentucky

UKnowledge

DNP Projects

College of Nursing

2019

\title{
Nurse-led positive psychology intervention is feasible in patients with heart failure
}

\author{
Erin Taylor \\ University of Kentucky, erin.baker3@uky.edu
}

Right click to open a feedback form in a new tab to let us know how this document benefits you.

\section{Recommended Citation}

Taylor, Erin, "Nurse-led positive psychology intervention is feasible in patients with heart failure" (2019). DNP Projects. 307.

https://uknowledge.uky.edu/dnp_etds/307

This Practice Inquiry Project is brought to you for free and open access by the College of Nursing at UKnowledge. It has been accepted for inclusion in DNP Projects by an authorized administrator of UKnowledge. For more information, please contact UKnowledge@lsv.uky.edu. 
Nurse-led positive psychology intervention is feasible in patients with heart failure

Submitted in Partial Fulfillment of the Requirements for the Degree of Doctor of Nursing Practice at the University of Kentucky

By

Erin A. Taylor, BSN, RN

Lexington, KY

Fall 2019 


\begin{abstract}
Introduction: Prevalence of heart failure (HF) in the US is projected to rise $46 \%$ by 2030 , resulting in more than 8 million people with HF. Negative psychologic states including depression and pessimism (negative future expectations) have been linked with poor cardiovascular outcomes, including HF. Despite the fact that optimism (positive future expectations) and other positive affective states have been associated with superior outcomes, there has been little focus on interventions designed to increase positive psychological states in patients with HF.
\end{abstract}

Objective: To test the acceptability and feasibility of a nurse-led positive psychology intervention, Best Possible Self (BPS).

Methods: A convenience sample of patients with HF were enrolled at an academic medical center in Kentucky. Baseline data including demographics, clinical information and optimism score was measured using the Life Orientation Test-Revised (LOT-R). The LOT-R is a validated and reliable measure of dispositional optimism, and scores range between 6-30, with higher scores indicating higher levels of optimism. The BPS intervention is relatively simple and does not require a psychologist to administer. The intervention requires participants to write/verbalize their imagined self in the future in terms of physical health or social relationships. The participants were asked to repeat the activity at home to prompt positive emotions and thoughts about oneself. Participants were contacted by telephone at 1 and 4 weeks to verify practice of the intervention.

Results: We approached 87 patients (inpatients and outpatients) to enroll 60 participants, with a yield rate of $69 \%$. Our sample was $62 \pm 13$ years of age, $46.7 \%$ male and $76 \%$ Caucasian. The mean LOT-R score from our sample was $22.3 \pm 5.1$ (range 6-30); the mean optimism subscale score was $12.0 \pm 2.6$ (range $3-15)$. The nurse-led intervention was determined 
to be feasible as $62 \%$ practiced the intervention at home, and acceptable with an attrition rate of $20 \%$ at 4 weeks.

Conclusion: Our data indicate that patients with heart failure are willing to participate and accept a nurse-led positive psychology intervention. These data will inform the development of a larger scale study to test positive psychology interventions on optimism scores and health-related outcomes. 


\section{Acknowledgements}

Chair: Martha Biddle, PhD, APRN, CCNS, FAHA

Mentor: Gretchen Wells, MD, PhD

Clinical Faculty: Paula Halcomb, DNP, MSN, APRN, ACNS-BC, TCRN 


\section{Table of Contents}

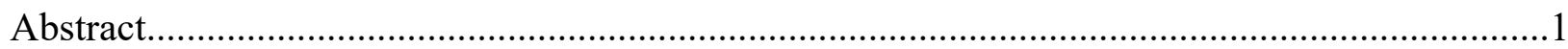

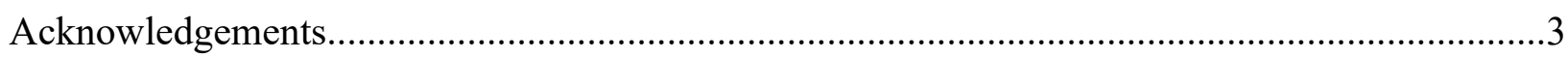

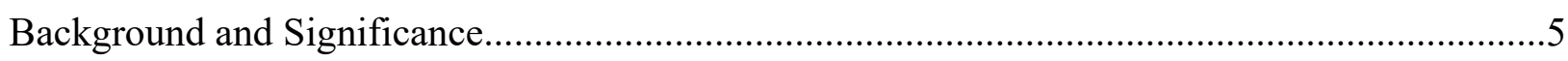

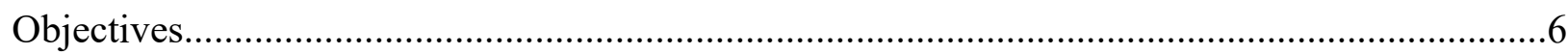

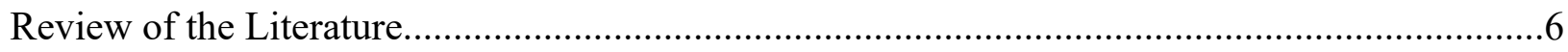

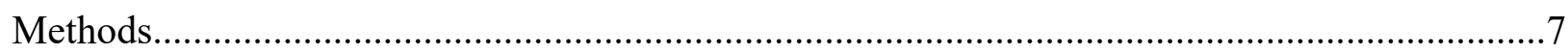

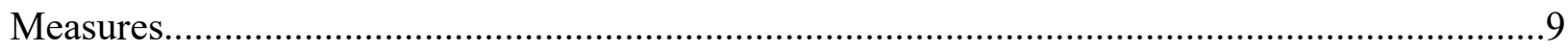

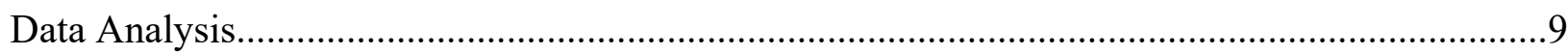

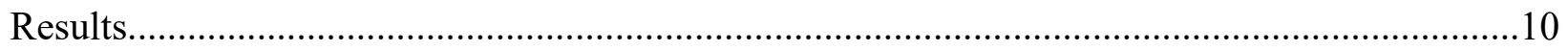

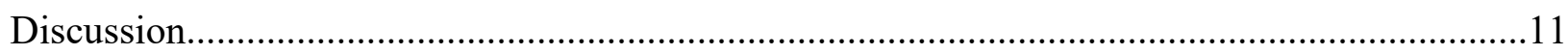

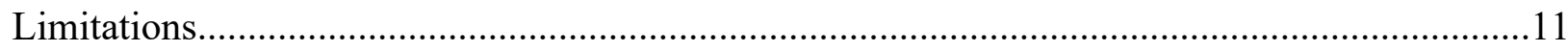

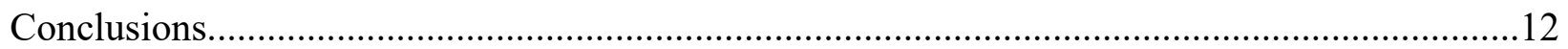

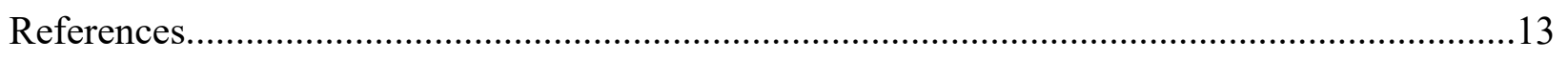

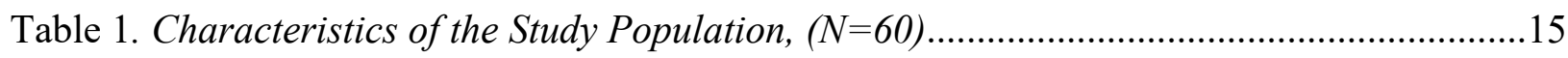




\section{Background and Significance}

Heart failure (HF) is one of the most common conditions affecting Americans, with 5.7 million adults in the US having the condition and is expected to rise $46 \%$ by 2030 , resulting in more than 8 million people with HF. ${ }^{1}$ Half of those who develop HF will die within five years of diagnosis. ${ }^{2}$ HF is a leading cause of hospitalization and increased health care costs in the US (approximately $\$ 40$ billion annually); 25\% of patients hospitalized with HF will be readmitted within 30 days. ${ }^{3,4}$ Despite medical advances and new therapies, mortality and morbidity rates remain high and the quality of life for those HF is reported as "poor". 1

Negative psychological states, including depression and pessimism (negative future expectations) are associated with HF, both of which leads to poor cardiovascular outcomes and increased mortality. ${ }^{3,5}$ It is important to consider how HF impacts psychological aspects of patients' lives, and what caregivers can do to improve mental health and outcomes.

Optimism (positive future expectations) has been correlated with significantly lower readmission rates. ${ }^{6}$ Optimism, however, has not been studied well in the HF patient population. Optimism, considered to be 'positive' psychology, is thought to be largely controlled by the individual and can be affected or increased through intentional activities ${ }^{7}$. The Best Possible Self (BPS) is a positive psychology intervention that can be conducted by a nurse to increase optimism. ${ }^{8}$ This intervention is an innovative approach that can be performed by someone who has already developed a therapeutic relationship with the patient in the clinical setting and does not require hiring additional staff or require a psychologist to perform the intervention.

The BPS intervention requires individuals to think about their life in the future where everything has turned out as well as it could have and then describe this best possible situation in writing. ${ }^{9}$ Writing and imagining this situation in the BPS activity can also increase optimism in terms of expecting favorable outcomes, as well as improve positive affect. ${ }^{7-10}$ 
Therefore, we sought to test the feasibility of conducting the BPS intervention by a nurse in patients with HF. Nurses develop a therapeutic relationship with their patients and using them to conduct the intervention would not require hiring additional resources.

\section{Objectives of the Project}

The primary objective of the feasibility study is to test a nursing-based BPS intervention as a positive psychological intervention to improve a patient's optimism with both ambulatory and hospitalized patients with heart failure.

\section{Review of Literature}

The Best Possible Self (BPS) intervention has been studied as an intervention to increase optimism and positive affect. ${ }^{7-9}$ Randomized controlled trials conducted thus far have examined the BPS intervention either with a control group or combined with another intervention. ${ }^{7,-11}$ The Life Orientation Test (LOT-R) is one instrument which has been used to measure dispositional optimism. ${ }^{9,10}$ This instrument has been tested primarily in females and older adults. ${ }^{7,9-11}$

The researchers reported the BPS intervention led to increased optimism. ${ }^{7-11}$ In one study, it was noted that participants' knowledge of the benefits of the intervention increased the effect of the intervention, and those who completed the intervention online were more affected by peer testimonials. $^{7}$ Another researcher reported when BPS was compared to gratitude, participants had in an increase in optimism and life satisfaction..$^{9}$ Also, writing about and imagining a BPS situation leads to an immediate benefit in optimism and positive future expectancies. ${ }^{10}$ In addition, participants who used daily imagery with BPS for two weeks, there were sustained increases in optimism (measured using the Life Orientation Test—LOT).${ }^{10}$ Beyond improving optimism, the BPS can reduce dysfunctional cognitions and reinstate positive affect and mood following a sad mood induction. ${ }^{11}$ 
The BPS was the most effective in increasing optimism as a psychological intervention, showing effect sizes substantially higher when compared to those who did not use this intervention. ${ }^{8}$ In addition, higher levels of optimism relate to improved physical and mental health benefits, such as decreasing rates of depression. ${ }^{8}$

Overall, there is evidence to indicate the BPS intervention improves optimism. Several gaps in the literature still exist, specifically, older adults (>age 65) have not been studied using the BPS intervention, nor has the BPS intervention been tested in a sample of patients with HF, nor has the intervention been delivered by nurses. Therefore, we designed a study to examine if a nurse-led BPS intervention is acceptable and feasible in a population of patients with HF.

\section{Methods}

This feasibility study was a single center study of both hospitalized and ambulatory patients with a primary or secondary diagnosis of heart failure. For hospitalized patients, we enrolled inpatients with HF on telemetry units within an academic medical center. In the ambulatory setting, we enrolled patients with HF from an outpatient general cardiology clinic. The enrollment plan was to enroll 30 patients from each setting to determine the feasibility of conducting this intervention in each setting.

Inclusion criteria included hospitalized adult patients (18 years and older). These patients were on one of three hospital service lines - Cardiology, Internal Medicine, and Family Medicine services. Ambulatory adult patients (18 years and older) presenting to the outpatient cardiology clinic were included. Patients were excluded if they were a) admitted for an acute coronary syndrome or a primary diagnosis of myocardial infarction; b) unable to provide informed consent related to an inability to communicate, such as being mechanically ventilated; 
c) terminally ill within the timeframe of the study (6 months) by an attending physician; d) under the care of or considering hospice/palliative care were also excluded.

Informed consent with a HIPAA consent was obtained at the time of enrollment after a full explanation of the study protocol was provided. We approached the patient in either the patient's room if they were inpatient, or in the clinic exam room if they were outpatient. Once the consent form was completed, a copy was provided to the patient and the signed document recorded in the data collection packet.

As this was a feasibility study, we documented all patients who were approached to determine if this intervention is realistic in both the hospitalized and ambulatory settings. The results of this study serve as preliminary data to enable the design of a large-scale trial.

The BPS intervention is designed for the patient to imagine the best possible outcome regarding physical health and social health over the next 1-5 years. The intervention is divided into two parts; the physical health portion of the intervention is explained during the initial visit with the patient, and asks the patient to imagine their best physical health as they see it in the next five years; the social health part of the intervention was explained during the initial interview and the patient was asked to complete the exercise again in one week. The study personnel collected baseline data during the initial enrollment visit, which included demographic data, optimism measures with the LOT-R, and conducted the first part of the BPS intervention. The patient was allowed to verbalize their best possible selves if they preferred that method over writing since some people in this population may have low literacy. At the 1-week follow up, the patient received a phone call from the study personnel, to see if they had completed the second part of the intervention related to social health. If they had not, the study personnel reviewed the intervention with them and encouraged them to either complete the exercise verbally over the 
phone or to write down the imagined best self-exercise on their own as soon as possible. At the 4-week follow up, the patient receives another phone call from the study personnel asking if they had been admitted to the hospital in the previous 4 weeks (since enrollment).

\section{Measures}

Study personnel collected basic demographic data via self-report. Cardiac health history with related comorbid conditions, current medications, and laboratory and echocardiogram results were obtained through chart review after consent was obtained. The patient completed the Life Orientation Test- Revised (LOT-R), the most commonly used validated and reliable tool to measure dispositional optimism. ${ }^{12}$ Scores can range from 6-30 with 30 being more optimistic (less pessimistic). The scale divides into two subscales, optimism and pessimism, each scoring between 3-15. It has been shown to be an independent predictor of later depression in the general population and has been tested in a large variety of languages and populations. ${ }^{12}$

\section{Data Analysis}

Enrollment, attrition, and feasibility rates were calculated using descriptive statistics. Clinical characteristics and demographics were recorded from self-report and from medical record review. All data was analyzed using SPSS statistics version 25. Statistical significance was established with a $p$-value of $<0.05$. We examined to see if there were any barriers to enrollment or follow-up. As the study objective was to evaluate the feasibility and acceptability of the BPS intervention, rather than the effect of the intervention, changes in dispositional optimism using the LOT-R were not retested.

One team member enrolled the participants and recorded the data on paper, and another recorded that information into a database system used by the facility. This data was then 
converted to SPSS format and analyzed. Once key findings were established, they were verified by another team member to ensure accuracy.

\section{Results}

Eighty-seven patients were screened for eligibility, all were either hospitalized or present in the outpatient cardiology clinic. We successfully enrolled a total of 60 participants in the study after approaching 87 patients (69\% yield rate). Clinical characteristics of the sample are provided

in Table 1 . The average age of our sample was $62 \pm 13$ years. Individuals were more likely to be female, white, overweight or obese, and most had completed high school and $45.1 \%$ at least some college. Regarding lifestyle behaviors, $50 \%$ were either current or former tobacco users, and the majority did not use alcohol or other substances. The average ejection fraction was $32.5 \%+13.5$ and $48.3 \%$ of the patients were diagnosed with coronary artery disease as the etiology for their heart failure. Only $11.6 \%$ of our participants were inpatients, while the remaining were recruited from the ambulatory cardiology clinic.

The mean optimism scores on the LOT-R for our sample was $22.3 \pm 5.1$ (range 6-30), with the optimism subscale mean score of $12.0 \pm 2.6$ (range 3-15). These scores indicate that our participants overall were fairly optimistic already.

The intervention was deemed acceptable as determined by the yield rate of patients screened eligible vs those who agreed to participate. $62 \%$ of participants practiced the intervention at home after the initial encounter either on their own or during the 1-week followup phone call, providing evidence that this nurse-led intervention is feasible. There was an overall attrition rate of $20 \%$ at 4 -weeks follow-up. These participants either asked not to continue with the study or were not able to be contacted for follow-up by phone. 


\section{Discussion}

This is the first study, to our knowledge, to test the feasibility for a nurse-led positive psychological intervention in patients with heart failure. Psychological well-being, including lifesatisfaction and optimism play a role in compliance with health behaviors and cardiovascular outcomes. ${ }^{13}$ Positive psychologic interventions increase optimism, hope, and other positive emotions, and this might encourage individuals to make better health decisions. ${ }^{13}$

Our findings demonstrate a nurse-led BPS intervention is feasible in the heart failure population in both inpatient and ambulatory settings. Inpatients were more difficult to enroll at this academic medical center as most were very sick with multiple comorbidities. Also, the inpatients were often out of their rooms for diagnostic procedures or were occupied with multiple providers or nursing staff. Many of the inpatients who were approached stated that they did not feel well enough to participate in research at that time.

Similar to other studies that used the BPS, our participants were able to complete the BPS exercise independently or with minimal guidance..$^{7-11,13}$ Our feasibility study deemed a nurse-led BPS intervention is acceptable and feasible in the HF patient population. Our study was similar

to the one by Celano et al. in that we were delivering a positive psychology intervention to individuals with HF, and their approach (using a telephone-delivered intervention) was also deemed acceptable to this population while supporting moderate improvements in positive affect, depression, and anxiety. ${ }^{13}$

\section{Limitations}

Our findings are limited in generalizability because this was a single center study at a large academic medical center with one cohort of patients diagnosed with HF. However, our 
sample is a representative sample of patients with HF and includes heterogeneity with regards to gender, age, education level, and EF for the HF population.

\section{Conclusion}

In conclusion, this study provides data that supports a positive psychology intervention delivered by nurses to patients with HF is feasible and acceptable. Future research is indicated in a larger sample to test the impact of a nurse-led BPS intervention on optimism and other health related variables as they relate to improving outcomes and reducing hospital readmission rates in patients with HF. The BPS is a minimal-risk intervention with potential for improving outcomes and could be very beneficial for nurses to incorporate into their everyday practice. 


\section{Reference List}

1. Savarese G, Lund LH. Global public health burden of heart failure. Psychiatry Research. 2017;3(1):105-110.doi: 10.15420/cfr.2016:25:2.

2. Centers for Disease Control and Prevention. Heart failure fact sheet. https://www.cdc.gov/dhdsp/data_statistics/fact_sheets/fs_heart_failure.htm. 2016.

3. Chapa DW, Akintade B, Heesook Son, et al. Pathophysiological Relationships Between Heart Failure and Depression and Anxiety. Critical Care Nurse. 2014;34(2):14-25. doi: $10.4037 / \operatorname{ccn} 2014938$.

4. Feltner C, Jones CD, Cené CW, et al. Transitional care interventions to prevent readmissions for persons with heart failure: a systematic review and meta-analysis. Annals of Internal Medicine. 2014;160(11):774-784. doi:10.7326/M14-0083.

5. Macale Cajanding RJ. The Effectiveness of a Nurse-Led Cognitive-Behavioral Therapy on the Quality of Life, Self-Esteem and Mood Among Filipino Patients Living With Heart Failure: a Randomized Controlled Trial. Applied Nursing Research. 2016;31:86-93. doi:10.1016/j.apnr.2016.01.002.

6. McCoy TH, Castro VM, Cagan A, Robertson AM, Kohane IS, \& Rerlis RH. Sentiment measured in hospital discharge notes is associated with readmission and mortality risk: An electronic health record study. Public Library of Science. 2015;10(8). doi:10.1371/journal.pone.0136341

7. Layous K, Nelson SK, \& Lyubomirsky S. What is the optimal way to deliver a positive activity intervention? The case of writing about one's best possible selves. Journal of Happiness Studies. 2012;14(2):635-654. http://dx.doi.org/10.1007/s10902-012-9346-2 
8. Malouff JM, Schutte NS. Can psychological interventions increase optimism? A metaanalysis. Journal of Positive Psychology. 2017;12(6):594-604.

doi:10.1080/17439760.2016.1221122.

9. Peters ML, Meevissen YMC, \& Hanssen MM. Specificity of the best possible self intervention for increasing optimism: Comparison with a gratitude intervention. Terapia Psicológica. 2013;31(1):93-100. http://dx.doi.org/10.4067/S0718-48082013000100009

10. Meevissen YM, Peters ML, Alberts HJ. Become more optimistic by imagining a best possible self: Effects of a two week intervention. Journal of Behavior Therapy \& Experimental Psychiatry. 2011;42(3):371-378. doi:10.1016/j.jbtep.2011.02.012.

11. Renner F, Schwarz P, Peters ML, \& Huibers, MJ. Effects of a best-possible-self mental imagery exercise on mood and dysfunctional attitudes. Psychiatry Research. 2014;215:105-110. doi: 10.1016/j.psychres.2013.10.033

12. Hinz A, Sander C, Glaesmer H, Brahler E, Zenger M, Hilbert A, Kocalevent RD. Optimism and pessimism in the general population: Psychometric properties of the Life Orientation Test (LOT-R). International Journal of Clinical and Health Psychology. 2017;17(2):161-170. doi: 10.1016/j.ijchp.2017.02.003.

13. Celano CM, Freedman ME, Beale EE, Gomez-Bernal F, Huffman JC. A positive psychology intervention to promote health behaviors in heart failure: A proof-of-concept trial. Journal of Nervous \& Mental Disease. 2018;206(10):800-808.

doi:10.1097/NMD.0000000000000883. 


\begin{tabular}{|c|c|c|c|}
\hline \multicolumn{4}{|c|}{ Table 1: Characteristics of Study Population } \\
\hline Characteristics & $\mathrm{N}[\%]$ or Mean $(\mathrm{SD})$ & Min & $\operatorname{Max}$ \\
\hline Age (years) & $62(13)$ & 34 & 92 \\
\hline \multicolumn{4}{|l|}{ Gender } \\
\hline Male & 28 [46.7] & & \\
\hline Female & $32[53.3]$ & & \\
\hline \multicolumn{4}{|l|}{ Setting } \\
\hline Inpatient & 8 [13.3] & & \\
\hline Outpatient & $52[86.7]$ & & \\
\hline BMI & $33.2(8.6)$ & 17.7 & 52.3 \\
\hline \multicolumn{4}{|l|}{ Education (Completed) } \\
\hline Grade School & $5[8.3]$ & & \\
\hline High School & $26[43.3]$ & & \\
\hline Some College & $7[11.7]$ & & \\
\hline College & 13 [21.7] & & \\
\hline Post-Graduate Studies & $7[11.7]$ & & \\
\hline \multicolumn{4}{|l|}{ Appalachian } \\
\hline Yes & 20 [33.3] & & \\
\hline \multirow{2}{*}{\multicolumn{4}{|c|}{ Race }} \\
\hline & & & \\
\hline White/Caucasian & 46 [76.7] & & \\
\hline Black/African American & 13 [21.7] & & \\
\hline Hispanic & $1[1.7]$ & & \\
\hline \multicolumn{4}{|l|}{ Marital Status } \\
\hline Single & 10 [16.7] & & \\
\hline Living Together, Unmarried & $2[3.3]$ & & \\
\hline Married & $22[36.7]$ & & \\
\hline Separated & $2[3.3]$ & & \\
\hline Divorced & $17[28.3]$ & & \\
\hline Widowed & $7[11.7]$ & & \\
\hline \multicolumn{4}{|l|}{ Tobacco } \\
\hline Current & 13 [21.7] & & \\
\hline Former & $17[28.3]$ & & \\
\hline \multirow{2}{*}{\multicolumn{4}{|c|}{ Alcohol }} \\
\hline & & & \\
\hline Daily & $3[5]$ & & \\
\hline 2-3 Times/Week & $1[1.7]$ & & \\
\hline Weekly & $2[3.3]$ & & \\
\hline Monthly & $5[8.3]$ & & \\
\hline Never & 49 [81.7] & & \\
\hline \multicolumn{4}{|l|}{ Substance Abuse } \\
\hline Yes & $6[10]$ & & \\
\hline No & $54[90]$ & & \\
\hline Ejection Fraction & $32.5(13.5)$ & 10 & 73 \\
\hline \multicolumn{4}{|l|}{ Coronary Artery Disease } \\
\hline Yes & 29 [48.3] & & \\
\hline No & $30[50]$ & & \\
\hline
\end{tabular}


